\title{
Awareness and Epidemiology of Chronic Hepatitis C Virus Infections in Florida
}

\author{
Emmanuel Thomas - Wei-Han Cheng · Douglas E. Dylla $\cdot$ \\ Steven E. Marx · Jana Carabino $\cdot$ Qingqing Xu
}

Received: October 12, 2021 / Accepted: December 1, 2021 / Published online: December 16, 2021

(C) The Author(s) 2021

\begin{abstract}
Introduction: Progress towards achieving hepatitis $\mathrm{C}$ virus (HCV) elimination in Florida has been hampered by barriers to screening, linkage to care, and treatment. This study aims to describe the HCV care cascade and patient characteristics in Florida.

Methods: This analysis combined HCV-related laboratory data and patient characteristics from two, large US laboratory datasets that included
\end{abstract}

\author{
E. Thomas $(\bowtie)$ \\ University of Miami Miller School of Medicine, 1550 \\ NW 10th Ave., PAP Bldg., Rm. 314, Miami, FL \\ 33136, USA \\ e-mail: EThomas1@med.miami.edu \\ W.-H. Cheng - D. E. Dylla · S. E. Marx · \\ J. Carabino - Q. Xu \\ AbbVie Inc., $1 \mathrm{~N}$. Waukegan Road, North Chicago, \\ IL 60064, USA \\ W.-H. Cheng \\ e-mail: wei-han.cheng@abbvie.com \\ D. E. Dylla \\ e-mail: douglas.dylla@abbvie.com \\ S. E. Marx \\ e-mail: steve.marx@abbvie.com \\ J. Carabino \\ e-mail: jana.carabino@abbvie.com \\ Q. $\mathrm{Xu}$ \\ e-mail: qingqing.xu@abbvie.com
}

individuals tested for HCV antibody (Ab) and HCV ribonucleic acid (RNA) viral load between January 2015 and December 2019. A decline in sequential HCV RNA viral loads was used to impute HCV treatment. Machine-learning algorithms were used to identify cured patients. The actual number of individuals with HCV Ab screening, and the number and percentage of persons who were HCV RNA-positive and treated, were calculated.

Results: The number of persons in Florida diagnosed as HCV RNA-positive was 31,659 in 2019. The number of individuals HCV Ab screened in 2019 was 1,024,379, an increase of $82.5 \%$ from 2015 . The percentage of $\mathrm{HCV} \mathrm{Ab}-$ positive individuals was $4.1 \%$, demonstrating a $16.2 \%$ decrease from 2015 . The percentage of HCV RNA-positive patients who were treated was $27.0 \%$, a $10.5 \%$ decrease from 2015 to 2019. Conclusion: An Ab positivity rate $>4$-times higher than national estimates with increased screening among baby boomers, but decreased screening among younger individuals, suggests risk-based screening is still common practice in Florida, despite universal screening recommendations. Public health efforts to decrease barriers to screening, linkage to care, and treatment are needed to reduce the burden of $\mathrm{HCV}$ in Florida and to ensure progress toward virus elimination.

Keywords: Disease eradication; Public health; Screening; Treatment; Virus elimination 


\section{Key Summary Points}

\section{Why carry out this study?}

There are several barriers to screening, linkage to care, and treatment that impede progress towards achieving hepatitis $\mathrm{C}$ virus (HCV) elimination in Florida.

Understanding the epidemiology of $\mathrm{HCV}$ infection in Florida and tracking the progress of meeting elimination targets provides an opportunity for the state to consider supporting plans that will reduce barriers to HCV screening and linkage to care.

This study analyzed data from two, large US laboratory datasets to describe the number of HCV infections and proportions of $\mathrm{HCV}$-infected individuals receiving treatment in the state of Florida.

\section{What was learned from this study?}

Despite universal screening recommendations, screening increased among baby boomers between 2015 and 2019 and decreased among younger individuals, suggesting risk-based screening is still common practice.

The proportion of $\mathrm{HCV}$-infected individuals receiving treatment decreased over time, suggesting that increased awareness and changes in policy are needed to support appropriate access to antiviral therapy.

In order to reach elimination goals in Florida, public health efforts to reduce barriers to screening and to support linkage to care are needed.

\section{INTRODUCTION}

Chronic hepatitis $\mathrm{C}$ virus (HCV) infection is associated with a substantial clinical, societal, and economic burden globally [1, 2], with an estimated 2.4 million people living with chronic infection in the United States (US) [3]. Florida has a documented heavy burden of this disease, with nearly $1 \%$ of the population $\mathrm{HCV}$ ribonucleic acid (RNA)-positive $(n / N=133,200 /$ $15,620,600 ; 0.85 \%)$, and is one of nine states that accounts for $52 \%$ of all HCV infections in the US [4]. Untreated HCV infection is a leading cause of morbidity and mortality [5]. Mean annual total all-cause medical costs increase by US $\$ 24,834$ for untreated versus treated patients with $\mathrm{HCV}$ infection [2]. The burden of $\mathrm{HCV}$ infection is especially high among people who inject drugs (PWID), with up to $70 \%$ of new HCV infections occurring among PWID in the US, partly due to the current opioid epidemic $[6,7]$. To address this increasing number of infections, specifically in younger patients, the Centers for Disease Control and Prevention, the US Preventive Services Task Force, the American Association for the Study of Liver Diseases, and the Infectious Diseases Society of America have now all endorsed universal, one-time screening for $\mathrm{HCV}$ in adults 18 years of age and older [8-10]. The burden of HCV infection disproportionately impacts Florida due to its large retiree population, as well as other high-risk populations, including non-Hispanic Black individuals $[11,12]$, and those individuals in correctional facilities $[13,14]$, especially incarcerated Hispanic persons [15]. Increased resources for improving knowledge of this disease, linkage to care, and subsequent treatment in these high-risk populations are needed to reduce the prevalence of chronic $\mathrm{HCV}$ [13, 16-18].

To address the global burden of HCV infection, the World Health Organization (WHO) has called for the elimination of viral hepatitis as a significant public health threat by 2030 [19]. With the WHO target year of elimination less than 9 years away, tracking progress towards elimination and identification of barriers, both nationally and within individual 
states, is important. In the US, there are marked differences between individual states in $\mathrm{HCV}$ prevalence and access to HCV treatment through government-funded payers that may prevent meaningful progress towards achieving elimination [11]. In Florida, there are challenges with HCV screening and diagnosis that inhibit progress towards elimination, including the lack of legislation to support opt-out testing for $\mathrm{HCV}$ similar to that for HIV, barriers at the provider level, and the restriction of funding to treat $\mathrm{HCV}$-positive incarcerated populations or to support harm reduction programs [20-22]. Understanding the epidemiology of $\mathrm{HCV}$ infection in Florida and tracking the progress of meeting elimination targets provides an opportunity for the state to consider supporting plans that will reduce barriers to screening and linkage to care. Therefore, the objectives of this study were to describe the number of individuals with HCV infection and to provide data on distinct aspects of the HCV care cascade [i.e., number of screenings, number of antibody (Ab) and RNA-positive individuals, and proportion of patients receiving treatment] in the state of Florida.

\section{METHODS}

\section{Study Design, Data Source, and Patient Population}

This retrospective analysis combined as-observed, de-identified data from two large US diagnostic laboratory companies that contain HCV-related laboratory results and patient characteristics from individuals who were tested for HCV $\mathrm{Ab}$ and HCV RNA viral load from January 1, 2015, to December 31, 2019. Patient age, geographic state (i.e., Florida), HCV Ab test, HCV RNA test, HCV genotype, fibrosis stage, and HIV coinfection status were also collected. Data from all individuals in the state of Florida who were screened for $\mathrm{HCV} \mathrm{Ab}$ and/or were tested for HCV RNA during this time were included in the analysis. Treatment initiation was assumed if an individual showed a decline in HCV RNA levels based on a viral load decline of at least $1.2 \times \log 10$ units from the time of their first positive HCV RNA test. Machinelearning algorithms were developed to identify patients who were cured and had been previously described [23, 24]. Briefly, machinelearning algorithms were validated using a separate set of data from 92,099 treated $\mathrm{HCV}$ individuals with medical and pharmacy claims available in the Symphony Health Solutions claims database from 2015 to 2019. Individuals identified by machine-learning algorithms as having been treated and cured based on successive viral load declines were classified as such in the following year (i.e., if identified as treated in 2016, they were labeled as cured in 2017). This data source did not include information on timing, type, or duration of treatment. Longitudinal methodology and imputation were applied to determine the number of HCV RNApositive individuals each year and to carry HCVrelated results forward. Specifically, a patient was included in the first and subsequent years of the study if they had an HCV RNA-positive test result and if they remained positive in subsequent years of testing. When a patient had a negative HCV RNA test result in subsequent years, they were counted as positive in the current year but negative in the following year(s).

\section{Outcomes}

The observed number of patients who received $\mathrm{HCV} \mathrm{Ab}$ screening and HCV RNA testing, and the number of HCV Ab screenings per 100,000 individuals in Florida between 2015 and 2019, are reported in this study. In addition, we present the observed absolute numbers and numbers per 100,000 persons who tested HCV Ab and HCV RNA-positive, as well as those who were subsequently treated. The percent change in observed number of individuals who were HCV Ab-screened, HCV Ab-positive, and HCV RNA-positive from year to year (i.e., 2015-2016, 2016-2017, etc.) and from 2015 to 2019 is reported. Where possible, we included the proportion of patients for a given measure stratified by age group. 


\section{Statistical Analysis}

For all $\mathrm{HCV} \mathrm{Ab}$ values, numbers presented are the observed total annual number. For HCV RNA data, numbers presented are accumulative (i.e., those who remained positive at the end of the previous year and any new cases identified in the current year make up the total number of patients for the current year). Any patients predicted by machine-learning algorithms to have been cured are removed from subsequent years. The number of observed HCV $\mathrm{Ab}$ screening and numbers of HCV Ab-positive and HCV RNA-positive individuals per 100,000 persons in each year were calculated by dividing the observed number of individuals by the US Census population estimates from 2015 to 2019, respectively. Data presented are descriptive, thus no causal inferences may be drawn from these data.

\section{Software}

Data cleaning and manipulation were performed using SAS 9.4 (Cary, NC, USA). Machine-learning algorithms were developed in $\mathrm{R}$ software ${ }^{\circledR}$ Foundation for Statistical Computing, Vienna, Austria).

\section{Ethics}

With permission, this study utilized de-identified data from two US laboratory datasets and, given that data were de-identified, no ethics committee approval was required.

\section{RESULTS}

\section{Observed HCV Ab Screening per 100,000 Persons in Florida from 2015 to 2019}

The number of patients screened for HCV Ab in this dataset was $1,024,379$ in 2019 , corresponding to 4809 individuals screened per 100,000 persons. This was an increase of $82.5 \%$ in the number of individuals screened, and a $73.3 \%$ increase in the number of $\mathrm{HCV} \mathrm{Ab}$ screening per 100,000 persons, since 2015 (Fig. 1a, b).

\section{Age Distribution of HCV Ab Screened Individuals in Florida from 2015 to 2019} In 2015, 32.5\% of HCV Ab screened individuals were $\geq 53$ years of age, whereas, in $2019,39.4 \%$ of $\mathrm{HCV} \mathrm{Ab}$ screened individuals were in this age strata (Fig. 1c), representing a 21.2\% increase over time. In contrast, the proportion of individuals between 30 and 52 years receiving $\mathrm{HCV}$ $\mathrm{Ab}$ screening gradually decreased, from $42.5 \%$ in 2015 to $38.8 \%$ in 2019 , an overall $8.7 \%$ decline. Individuals $<30$ years of age made up 25.0\% of persons screened for HCV Ab in 2015 and only $21.7 \%$ of persons screened in 2019 , representing a $13.1 \%$ decline in screening for this population over time.

\section{Observed HCV Ab Positivity from 2015 to 2019}

Although the number of HCV Ab-screened individuals increased substantially (82.5\%;
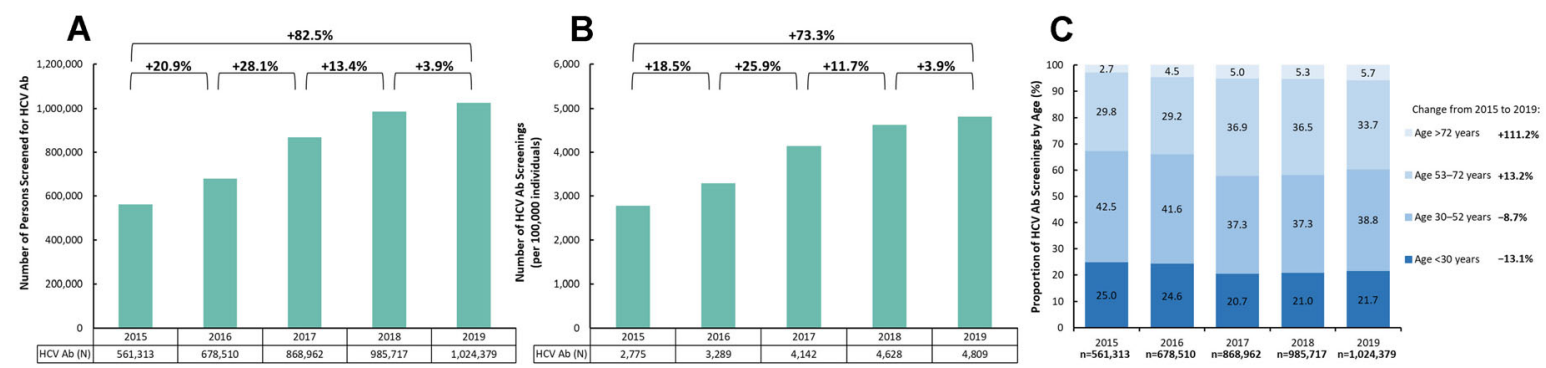

Fig. 1 Change in number of persons screened for HCV $\mathrm{Ab}$ (a), proportion of $\mathrm{HCV} \mathrm{Ab}$ screened persons per 100,000 individuals $(\mathbf{b})$, and age distribution of HCV Ab- screened persons (c) from 2015 to 2019. $A b$ antibody, $H C V$ hepatitis $\mathrm{C}$ virus 


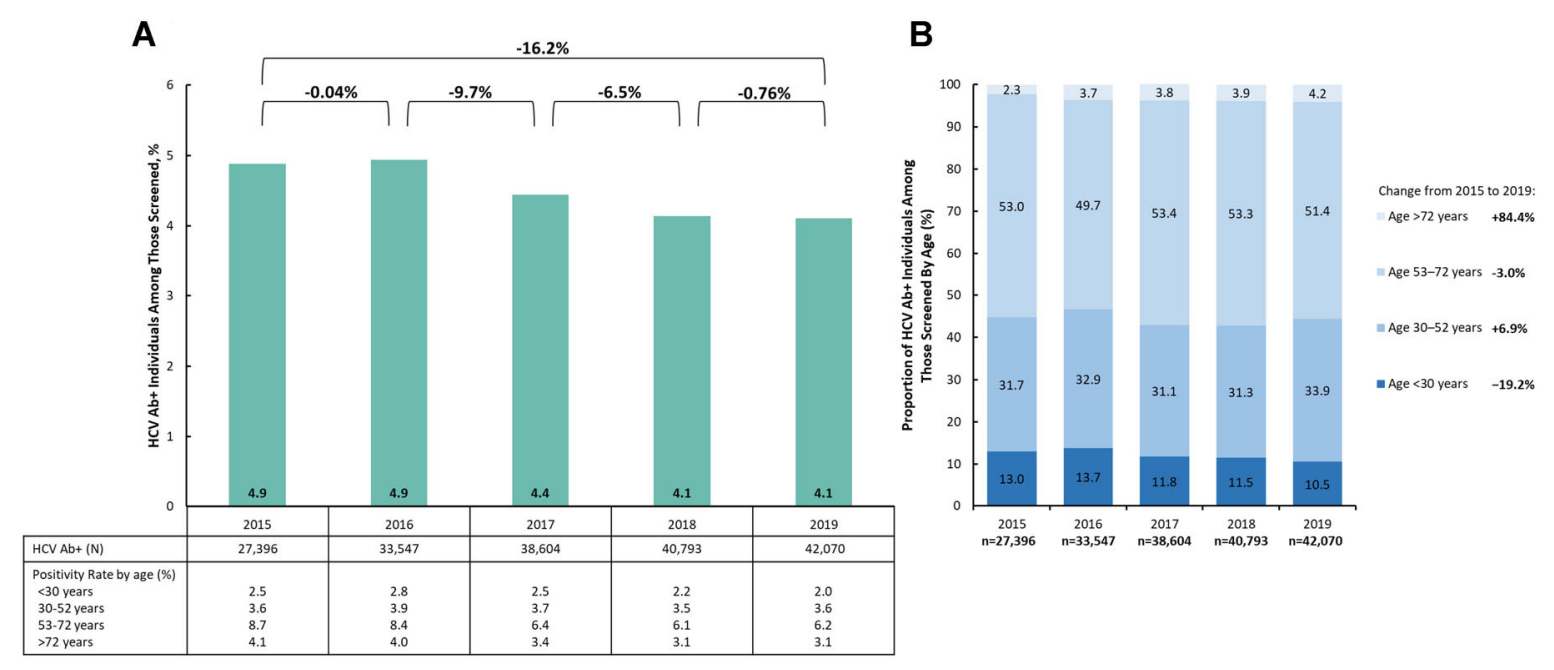

Fig. 2 Change in number of HCV Ab-positive persons and proportion of HCV Ab positivity among those screened by age strata (a) and age distribution of HCV Ab-positive individuals (b) from 2015 to 2019. Ab antibody, $H C V$ hepatitis $\mathrm{C}$ virus

Fig. 1a), the proportion of screened individuals who were $\mathrm{HCV}$ Ab-positive decreased 16.2\% from $4.9 \%$ in 2015 to $4.1 \%$ in 2019 (Fig. 2a). Despite the modest decrease in the percentage of individuals who were HCV Ab-positive, the expanded screening efforts identified 14,674 more HCV Ab-positive individuals in 2019 when compared with 2015.

\section{Change in HCV Ab Positivity by Age Strata from 2015 to 2019}

When broken down by age (Fig. 2a), HCV Ab positivity remained relatively stable from 2015 to 2019 for persons aged $<30$ years $(2.0-2.5 \%)$ or 30-52 years (3.5-3.7\%). HCV Ab positivity in persons 53-72 years of age gradually declined from $8.7 \%$ in 2015 to $6.2 \%$ in 2019 . Similarly, positivity modestly declined in individuals older than 72 years, from $4.1 \%$ in 2015 to $3.1 \%$ in 2019.

\section{Age Distribution of $\mathrm{HCV}$ Ab Positive Individuals from 2015 to 2019}

Between 2015 and 2019, individuals aged 53-72 constituted the highest proportion (49.7-53.0\%) in any given year (Fig. 2b). Individuals below 30 years of age comprised $13.0 \%$ of all HCV Ab-positive persons in 2015 compared with $10.5 \%$ in 2019 , a $19.2 \%$ decrease.
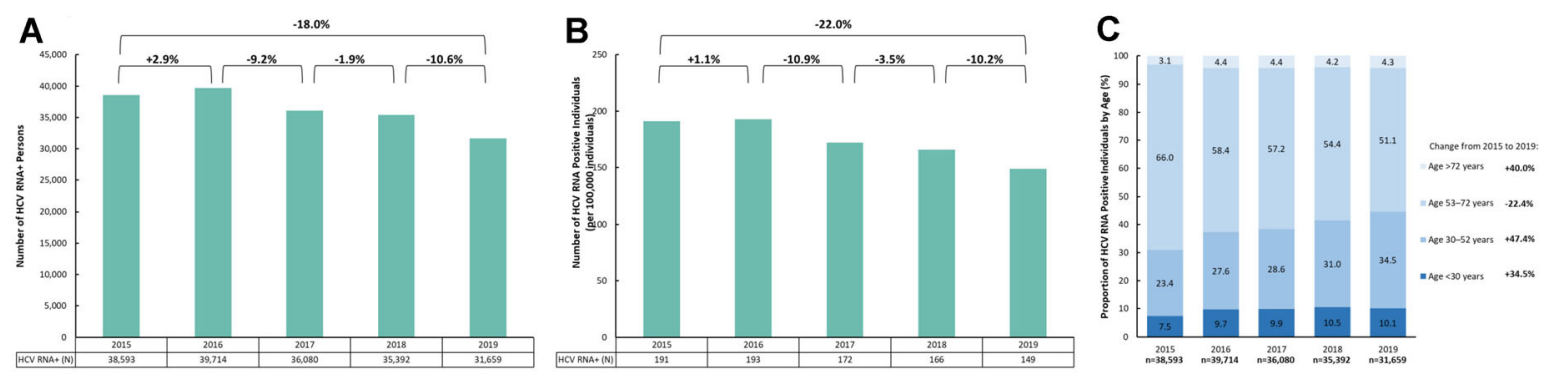

Fig. 3 Change in number of HCV RNA-positive persons (a), rate of HCV RNA positivity among individuals screened (b), and age distribution of HCV RNA-positive individuals (b) from 2015 to 2019. $H C V$ hepatitis $\mathrm{C}$ virus, $R N A$ ribonucleic acid 


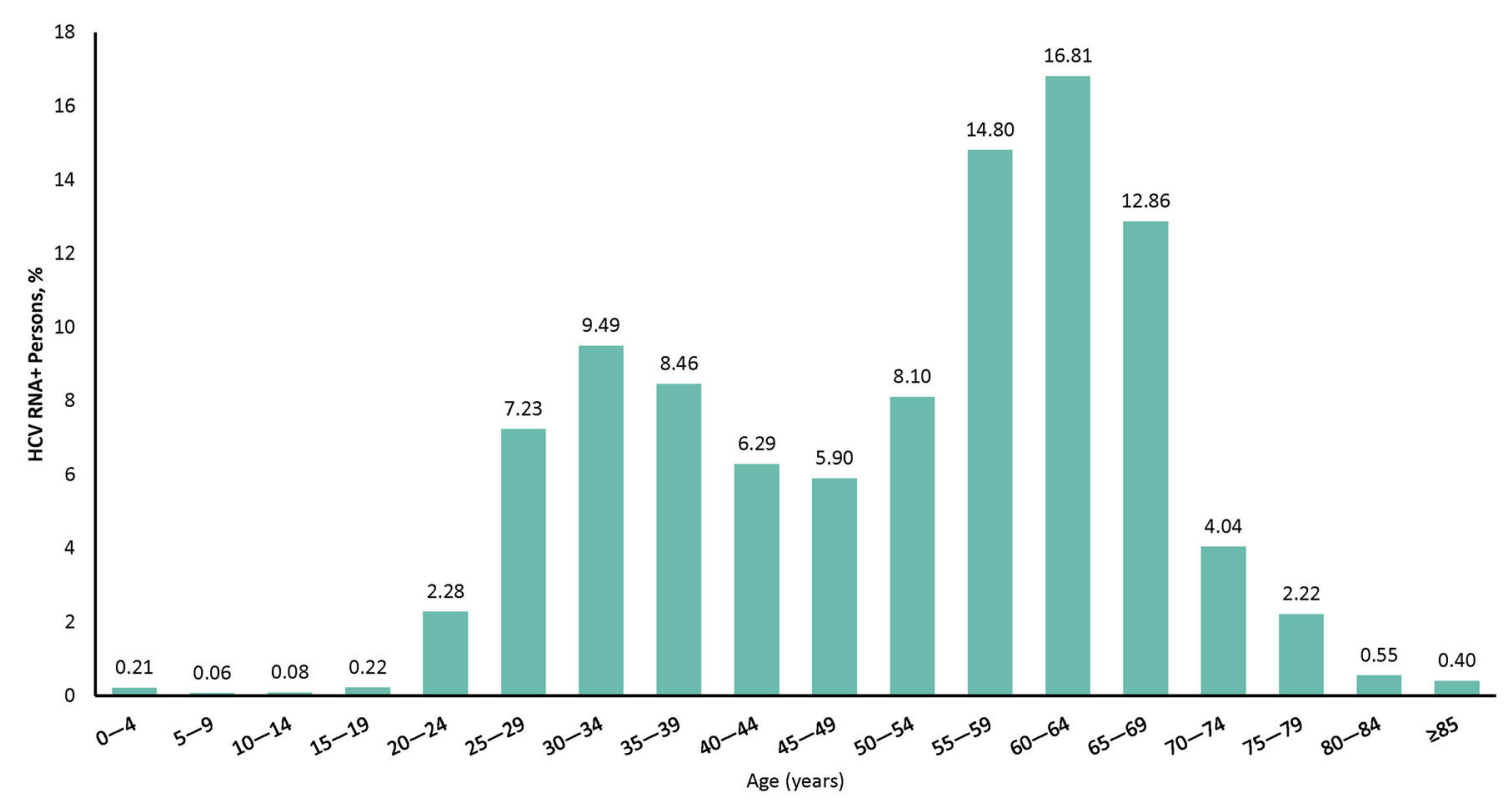

Fig. 4 Age distribution of HCV RNA-positive individuals in Florida in 2019. $H C V$ hepatitis $\mathrm{C}$ virus, $R N A$ ribonucleic acid

\section{Diagnosed HCV RNA Positive Estimates from 2015 to 2019}

The number of individuals in Florida who remained HCV RNA-positive and who would benefit from HCV treatment was 31,659 in 2019 (Fig. 3a). This corresponds to 149 HCV RNApositive individuals per 100,000, based on 2019 Florida census data (Fig. 3B). The number of individuals who were HCV RNA-positive decreased by $18.0 \%$ from 2015 to 2019 (Fig. 3a). Similarly, there was a $22.0 \%$ decrease in the number of HCV RNA-positive individuals per 100,000 persons between 2015 and 2019 (Fig. 3b).

\section{Change in Age Distribution of HCV RNA Positive Patients from 2015 to 2019}

The age distribution of HCV RNA-positive individuals in Florida in 2019 is depicted in Fig. 4. Approximately $1 / 3$ of HCV RNA-positive individuals were between 55 and 69 years old, with another third between 25 and 44 years old.

Among individuals who tested HCV RNApositive, the proportion of individuals aged $<30$ years increased $34.5 \%$ from $7.5 \%$ in 2015 to $10.1 \%$ in 2019 (Fig. 3c). Persons
30-52 years of age also saw an increase of $47.4 \%$, from $23.4 \%$ in 2015 to $34.5 \%$ in 2019 . Baby boomers (53-72 years) constituted $66 \%$ of HCV RNA-positive individuals in 2015, and decreased to $51.1 \%$ in 2019 , a $22.4 \%$ decrease.

\section{Percentage of Individuals Treated} from 2015 to 2019

A total of 8556 HCV RNA-positive individuals received treatment in 2019, which accounted for $27.0 \%$ of all persons who tested HCV RNApositive (Fig. 5a). The percentage of HCV RNApositive individuals who were treated decreased by $10.5 \%$ from 2015 to 2019 (Fig. 5a). When stratified by age, $57.8 \%$ of all individuals receiving treatment were 53-72 years old, with $30.4 \%$ of treated individuals aged $30-52$ years (Fig. 5b). Individuals $\leq 29$ or $\geq 73$ years old made up $8.0 \%$ and $4.0 \%$, respectively, of individuals receiving treatment.

\section{DISCUSSION}

This study has presented an overview of the number of patients screened, diagnosed, and 

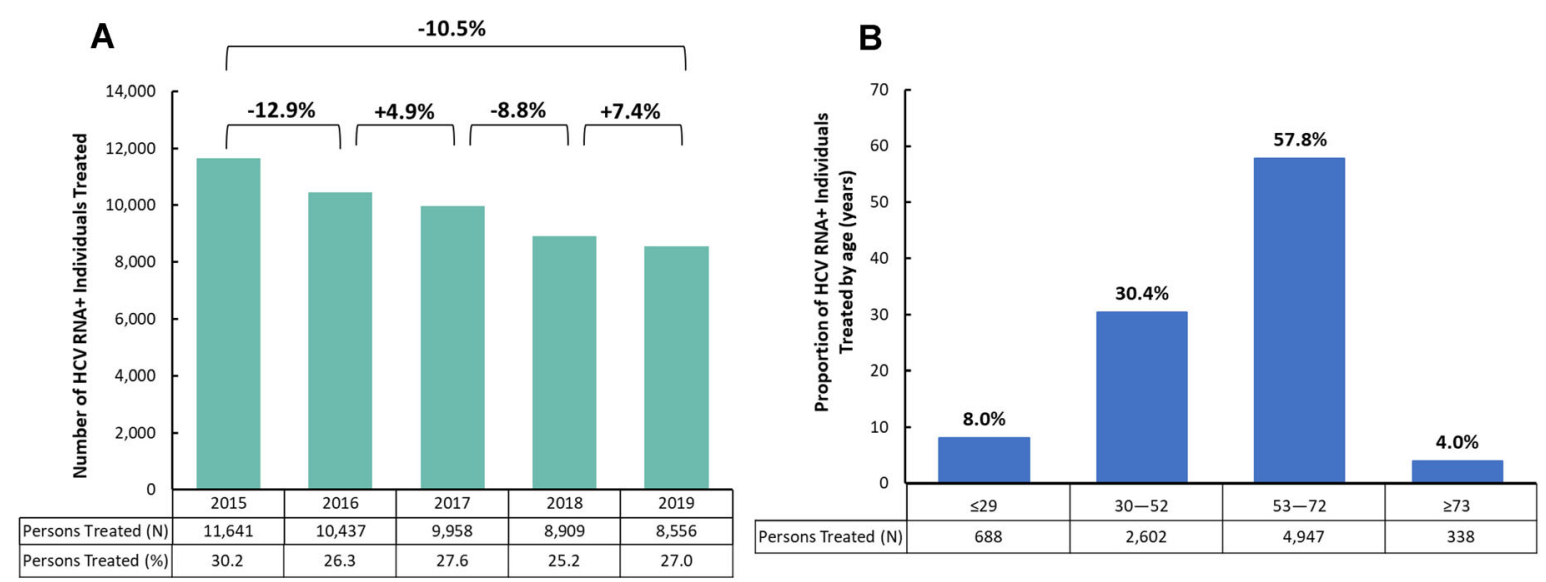

Fig. 5 Change in rate of HCV treatment among HCV RNA-positive individuals in Florida from 2015 to 2019 (a) and proportion of patients treated in 2019 by age group (b). HCV hepatitis $\mathrm{C}$ virus

treated for $\mathrm{HCV}$ infection in Florida from a large, unique dataset, and has highlighted the improvements needed to reach the WHO goal of eliminating HCV by 2030. The number of persons screened for $\mathrm{HCV} \mathrm{Ab}$ in Florida increased $82.5 \%$ between 2015 and 2019, primarily among baby boomers; screening decreased among younger individuals $(-13.1 \%$ among persons $<30$ years old). The proportion of HCV Ab-positive persons among those screened dropped $16.2 \%$ from 2015 to 2019. Likewise, the proportion of HCV RNA-positive persons among those screened dropped 18.0\% from 2015 to 2019. Based on HCV RNA data, there were approximately 149 infections per 100,000 persons in 2019. When stratified by age, our data showed that both $\mathrm{Ab}$ and RNA positivity increased in individuals $30-52$ years old and decreased among those 53-72 years old (i.e., baby boomers), from 2015 to 2019 . Moreover, we showed a bimodal age distribution in the number of HCV RNA-positive persons, with most individuals in the 25-44 and 50-69 years old categories. In this study, only $27.0 \%$ of HCV RNA-positive individuals in Florida were treated in 2019 , a $10.5 \%$ decrease from 2015 . Of those receiving treatment, over $80 \%$ were between 30 and 72 years old (30-52 years: $30.4 \%$; 53-72 years: $57.8 \%$ ).

Adopting universal screening recommendations should produce considerable drops in the proportion of $\mathrm{HCV}$ Ab-positive persons among those screened, yet Florida's rate only dropped $16.2 \%$ from 2015 to 2019 , suggesting that riskbased screening is still common practice. Similarly, the proportion of HCV RNA-positive persons among those screened dropped $18.0 \%$. We estimated 149 infections per 100,000 persons, which is higher than the Florida Department of Health's 2019 estimate of 94 infections per 100,000 persons, derived from the state's reportable disease surveillance system; our study reported 31,659 HCV RNA-positive individuals in 2019, versus the Florida Department of Health's report of 19,917 [25]. However, both studies derived data without extrapolation, thus the rates identified are likely underestimations. The current study demonstrated a bimodal age distribution of HCV RNA-positive persons, suggesting that screening efforts cannot simply target one population, further bolstering the need for universal screening. In 2019, less than one-third of HCV RNA-positive patients received treatment, similar to the $26.8 \%$ of $\mathrm{HCV}$ RNA-positive patients nationally that received treatment in 2019 [24]. The decline in treatment rates may be partly due to the fact that fewer patients are treated year after year. In this study, treatment rate was calculated by the total number of persons treated divided by the total number of persons diagnosed as HCV RNApositive (i.e., based on viral load 
measurements). Thus, treatment rates were also affected by the total number of persons diagnosed as HCV RNA-positive, which decreased from 2015 to 2019. It is also possible that treatment rates declined due to a lack of perceived importance of treating HCV in younger and/or asymptomatic patients. Likewise, rises in HCV infections have been linked to the opioid epidemic, and it is possible that treating addiction is prioritized over treating concurrent HCV [7]. Treatment estimates in Florida are in line with recently published national estimates [24], despite data from the current study showing that the number of $\mathrm{HCV} \mathrm{Ab}$ screenings per 100,000 persons in Florida is nearly double that of national rates (4809 vs. 2417$)$ and that the number of HCV RNA-positive individuals per 100,000 persons in Florida is also higher (149 vs. 110) [24], thus suggesting that improvements in linkage to care and treatment are needed.

In Florida, at the time of this study, specific barriers to treatment, particularly in urban environments, included prescriber/provider restrictions (required specialists), sobriety restrictions (1-month sobriety prior to treatment), lack of funding to treat HCV-positive incarcerated populations, and a high number of Medicaid enrollees [21, 26]. As of 2020, Florida had removed prescriber restrictions, but still required 1 month of sobriety to access treatment under Medicaid; there were no fibrosis stage restrictions. Florida is 1 of 13 states that maintains sobriety restrictions under Medicaid [26-28], despite clinical guidelines stating that current or recent drug use is not a contraindication to treatment [6]. Moreover, Florida is 1 of 9 states (California, New York, Tennessee, North Carolina, Ohio, Pennsylvania, Michigan, and Texas) that contain $52 \%$ of all HCV-infected individuals [4]. As of 2020, most of these states had no restrictions on fibrosis staging (except TX) in order to receive treatment, but 7 had sobriety requirements (no restrictions in CA or $\mathrm{OH})$. Rates of treatment in these states is in line with national estimates [24], except in Ohio (10\%) and Michigan (15\%) [29]. In Ohio, Medicaid did not cover treatment for patients with low fibrosis scores $(<\mathrm{F} 2)$, and only approved treatment once disease progressed. As of 2019, the Ohio Department of Medicaid approved treatment in earlier stages of disease, which should increase treatment rates [30]. Michigan Medicaid launched the State Plan on Eliminating HCV in 2020, which included requested partnerships with drug manufacturers to eliminate the cost barriers of direct-acting antiviral treatments [31]. Florida is not a Medicaid expansion state, which impacts the number of patients, especially the uninsured, who are able to afford and access treatment. A major obstacle to treating uninsured patients is cost, resulting in fewer patients receiving treatment [32]. Yet, $\mathrm{HCV}$-infected patients, regardless of insurance status, achieve comparable clinical outcomes and cure rates when given access to treatment, suggesting that patient assistance programs that reduce the cost of treatment also offer a clinical benefit. Removing HCV treatment restrictions in Florida, and nationally, may significantly boost elimination efforts. For more information regarding screening, positivity, and treatment trends by state please visit http://www. MappingHepC.com [29].

Aside from treatment costs, additional barriers to screening and testing identified by a study in Miami, Florida, included lack of education regarding $\mathrm{HCV}$ care, the cost of testing and implementing screening programs, and provider uncertainty regarding patient insurance status [22]. HCV-related or injection drug use-related stigma have also been shown to greatly impact care-seeking behaviors and, yet once diagnosed, only a small number of patients are successfully linked to care [5]. Poor patient retention may result from long waiting times for specialist referrals or test results, requirement for multiple follow-up appointments, and low patient motivation [33]. Moreover, some populations (e.g., incarcerated individuals, PWID, and minorities) are disproportionately impacted by $\mathrm{HCV}$ and may face more specific barriers. For example, treatment for incarcerated individuals for whom $\mathrm{HCV}$ infection is endemic has been hampered by judicial rulings and state funding decisions that guide healthcare spending [34, 35]. Among minorities in an urban setting (56\% Black), $>70 \%$ of HCV patients had not initiated $\mathrm{HCV}$ therapy and frequently cited psychosocial factors, provider barriers, or insurance-related 
challenges as barriers to treatment [21]. Decentralizing and simplifying HCV care to include point-of-care testing and community-based care are vital to elimination efforts, as they may mitigate some barriers (e.g., long wait times, stigma, need for specialists) [36]. Increased HCV-specific funding within the Florida Department of Health is needed to further improve patient engagement, screening, diagnosis, linkage to care, and treatment rates, particularly among high-risk groups [20].

Florida is currently taking steps to overcome these barriers to screening, diagnosis, and treatment, such as removing treatment restrictions and establishing a hepatitis $\mathrm{C}$ elimination program to increase screening and linkage to care and to reduce barriers to access for directacting antivirals. The program endeavors to specifically reduce barriers affecting underserved populations through the use of public and private partnerships [20]. Other states have initiated HCV elimination programs to achieve the WHO targets by 2030, and the data and discussion presented here support the subsequent establishment of similar efforts in Florida [37]. Other solutions to improve treatment access include expanding Medicaid eligibility criteria, reducing stigma, and increasing patient engagement and provider availability [38]. Altogether, these may provide opportunities to overcome the existing barriers to achieving elimination in Florida.

The limitations of this study are that data presented are from two laboratory services and do not attempt to quantify the undiagnosed population or to account for patients identified by other hospital laboratory services. Likewise, the geographic areas of the two laboratory companies varied by year due to contractual agreements, thus geographical data from one year may not exactly match that of the next. The HCV prevalence data prior to 2015 were not captured in our study. Moreover, details pertaining to the specific context of testing or treatment (i.e., inpatient, outpatient, etc.) or types or durations of treatments prescribed were not available. The use of viral load as a proxy for cured individuals could be inaccurate owing to insufficient follow-up time. No causal inferences, including specific prior $\mathrm{HCV}$ treatment experience, including regimen (e.g., direct-acting antiviral or interferon-based), or duration may be drawn from this descriptive analysis.

\section{CONCLUSION}

In summary, $\mathrm{HCV}$ Ab screening in Florida has increased over time; however, the proportion of persons testing positive over the same timeline has decreased, highlighting the need for universal screening and opt-out HCV testing. Treatment rates have decreased over time, suggesting that increased awareness and changes in policy are needed to support appropriate access to antiviral therapy. Favorable modifications to current policies would include reducing payer and sobriety restrictions to advance progress towards HCV elimination. Furthermore, public health efforts to decrease barriers to screening and to support linkage to care are needed to reduce the burden of HCV infection in Florida.

\section{ACKNOWLEDGEMENTS}

The authors would like to acknowledge Oscar A. Hayes for carrying out the statistical analysis and generating the study report; and Shivaji R. Manthena for performing the machine-learning prediction of treated and cured patients.

Funding. This work was supported by AbbVie Inc. AbbVie sponsored the study; contributed to the design; participated in collection, analysis, and interpretation of data; and in writing, reviewing, and approval of the final version. AbbVie Inc. also funded the Rapid Service Fee for publication. No honoraria or payments were made for authorship.

Medical Writing Assistance. Medical writing assistance was provided by Brandy Menges, PhD, and Samantha D. Francis Stuart, PhD, of Fishawack Facilitate Ltd, part of Fishawack Health, and was funded by AbbVie Inc., North Chicago, IL.

Authorship. All named authors meet the International Committee of Medical Journal 
Editors (ICMJE) criteria for authorship for this article, take responsibility for the integrity of the work, and have given their approval for this version to be published. No honoraria or payments were made for authorship.

Author Contributions. Emmanuel Thomas, Douglas E. Dylla, and Jana Carabino have made substantial contributions to the conception and design of the study and interpretation of the study results; Wei-Han Cheng, Steven E. Marx, and Qingqing $\mathrm{Xu}$ have made substantial contributions to the conception or design of the work, the acquisition, analysis, and interpretation of data; all authors have drafted the work and revised it critically for important intellectual content.

Disclosures. Emmanuel Thomas: AbbVie: Scientific Advisory Boards, Gilead Sciences: Scientific Advisory Boards and Grant support, American Liver Foundation: National Board of Directors. Wei-Han Cheng, Douglas E. Dylla, Steven E. Marx, Jana Carabino, and Qingqing $\mathrm{Xu}$ : AbbVie employees and may own AbbVie stock/options.

Compliance with Ethics Guidelines. With permission, this study utilized de-identified data from two US laboratory datasets. Because the data were de-identified, no ethics committee approval was required.

Data Availability. The datasets generated during and/or analyzed during the current study are available from the corresponding author on reasonable request.

Open Access. This article is licensed under a Creative Commons Attribution-NonCommercial 4.0 International License, which permits any noncommercial use, sharing, adaptation, distribution and reproduction in any medium or format, as long as you give appropriate credit to the original author(s) and the source, provide a link to the Creative Commons licence, and indicate if changes were made. The images or other third party material in this article are included in the article's Creative Commons licence, unless indicated otherwise in a credit line to the material. If material is not included in the article's Creative Commons licence and your intended use is not permitted by statutory regulation or exceeds the permitted use, you will need to obtain permission directly from the copyright holder. To view a copy of this licence, visit http://creativecommons.org/ licenses/by-nc/4.0/.

\section{REFERENCES}

1. Polaris Observatory HCVC. Global prevalence and genotype distribution of hepatitis $C$ virus infection in 2015: a modelling study. Lancet Gastroenterol Hepatol. 2017;2(3):161-76.

2. Reau N, Vekeman F, Wu E, Bao Y, Gonzalez YS. Prevalence and economic burden of extrahepatic manifestations of hepatitis $\mathrm{C}$ virus are underestimated but can be improved with therapy. Hepatol Commun. 2017;1(5):439-52.

3. CDC. Viral hepatitis surveillance 2019. https:// www.cdc.gov/hepatitis/statistics/2017surveillance/ index.htm. Accessed Mar 2021.

4. Rosenberg ES, Rosenthal EM, Hall EW, Barker L, Hofmeister MG, Sullivan PS, et al. Prevalence of hepatitis $C$ virus infection in US States and the District of Columbia, 2013 to 2016. JAMA Netw Open. 2018;1(8):e186371-471.

5. WHO. Global hepatitis report 2017. http://www. who.int/hepatitis/publications/global-hepatitisreport2017/en/. Accessed Sept 2021.

6. AASLD-IDSA. Management of acute HCV infection. Key populations: identification and management of $\mathrm{HCV}$ in people who inject drugs. https://www. hcvguidelines.org/unique-populations/pwid. Accessed Sept 2021.

7. Zibbell JE, Asher AK, Patel RC, Kupronis B, Iqbal K, Ward JW, et al. Increases in acute hepatitis $C$ virus infection related to a growing opioid epidemic and associated injection drug use, United States, 2004 to 2014. Am J Public Health. 2018;108(2):175-81.

8. Schillie S, Wester C, Osborne M, Wesolowski L, Ryerson $\mathrm{AB}$. CDC recommendations for hepatitis $\mathrm{C}$ screening among adults - United States, 2020. MMWR Recomm Rep Morb Mortal Wkly Rep. 2020;69(2):1-17.

9. AASLD-IDSA. Recommendations for testing, managing, and treating hepatitis C. http://www. hcvguidelines.org/full-report/hcv-testing-and-linkagecare. Accessed Sept 2021. 
10. Force UPST. Screening for hepatitis C virus infection in adolescents and adults: US Preventive Services Task Force recommendation statement. JAMA. 2020;323(10):970-5.

11. Bradley H, Hall EW, Rosenthal EM, Sullivan PS, Ryerson $\mathrm{AB}$, Rosenberg ES. Hepatitis $\mathrm{C}$ virus prevalence in 50 U.S. States and D.C. by sex, birth cohort, and race: 2013-2016. Hepatol Commun. 2020;4(3): 355-70.

12. HHS. Hepatitis C disparities among African Americans 2017. https://www.hhs.gov/hepatitis/blog/ 2017/02/27/hepatitis-c-disparities-among-africanamericans.html. Accessed Mar 2021.

13. Crowley D, Murtagh R, Cullen W, Keevans M, Laird E, McHugh T, et al. Evaluating peer-supported screening as a hepatitis $\mathrm{C}$ case-finding model in prisoners. Harm Reduct J. 2019;16(1):42.

14. Spaulding AC, Anderson EJ, Khan MA, TabordaVidarte CA, Phillips JA. HIV and HCV in U.S. prisons and jails: the correctional facility as a bellwether over time for the community's infections. AIDS Rev. 2017;19(3):134-47.

15. Ibañez GE, Whitt E, Rosa MDL, Martin S, O'Connell D, Castro J. Developing a culturally appropriate HIV and hepatitis $\mathrm{C}$ prevention intervention for latino criminal justice clients. J Correct Healthc. 2016;22(3):206-17.

16. Auf R, Cano M, Selim M, O'Connell D, Martin S, Ibañez GE. Hepatitis $C$ virus and hispanic criminal justice clients: a missed opportunity. J Immigr Minor Health. 2020;22(4):701-7.

17. Heffernan A, Cooke GS, Nayagam S, Thursz M, Hallett TB. Scaling up prevention and treatment towards the elimination of hepatitis C: a global mathematical model. Lancet. 2019;393(10178): 1319-29.

18. Morris MD, Brown B, Allen SA. Universal opt-out screening for hepatitis $\mathrm{C}$ virus $(\mathrm{HCV})$ within correctional facilities is an effective intervention to improve public health. Int J Prison Health. 2017;13(3-4):192-9.

19. WHO. Global health sector strategy on viral hepatitis 2016-2021 2020. https://www.who.int/ publications/i/item/WHO-HIV-2016.06. Accessed Dec 2021.

20. Florida Viral Hepatitis Planning Group. FHPP. The Florida hepatitis prevention action plan 2016-2020 2016. http://www.floridahealth.gov/diseases-andconditions/hepatitis/_documents/hep-preventionaction-plan-2016.pdf. Accessed Sept 2021.
21. Malespin M, Harris C, Kanar O, Jackman K, Smotherman C, Johnston A, et al. Barriers to treatment of chronic hepatitis $\mathrm{C}$ with direct acting antivirals in an urban clinic. Ann Hepatol. 2019;18(2):304-9.

22. Feldman EB, Balise R, Schiff E, Whitehead N, Thomas E. Barriers to hepatitis $C$ screening in a minority population: a comparison of hepatitis $\mathrm{C}$ and human immunodeficiency virus screening rates at a community STD clinic in Miami, Florida. J Community Health. 2017;42(5):921-5.

23. Chirikov VV, Marx SE, Manthena SR, Strezewski JP, Saab S. Development of a comprehensive dataset of hepatitis $C$ patients and examination of disease epidemiology in the United States, 2013-2016. Adv Ther. 2018;35(7):1087-102.

24. Reau N, Sulkowski MS, Thomas E, Sundaram V, Xu $\mathrm{Q}$, Cheng WH, et al. Epidemiology and clinical characteristics of individuals with hepatitis $C$ virus infection in the United States, 2017-2019. Adv Ther. 2021;38(12):5777-90.

25. Florida Department of Health. Epidemiology of hepatitis B and C in Florida, 2019. 2021. http:// www.floridahealth.gov/diseases-and-conditions/ hepatitis/hepatitis-general-information.html. Accessed Dec 2021.

26. NVHR, CHLPI. Hepatitis C: state of Medicaid access 2020. http://stateofhepc.org. Accessed May 2021.

27. Waters P, Greenwald R, Ninburg M, Simmons A. State policies limiting progress towards HCV elimination in the U.S. National Viral Hepatitis Roundtable. 2020.

28. Greenwald R, Waters P, Cayer S. Enforcement of legal remedies to secure hepatitis $C$ virus treatment with direct-acting antiviral therapies in correctional facilities and Medicaid programs. Public Health Rep. 2020;135(1_suppl):44s-9s.

29. MappingHepC. Interactive map 2020. https:// mappinghepc.com/maps. Accessed Sept 2021.

30. Christ G. Ohio Department of Medicaid to treat those with Hepatitis C earlier. The Plain Dealer. 2018.

31. MDHHS. Michigan's state plan on eliminating hepatitis C. 2021. https://www.michigan.gov/ documents/mdhhs/MDHHS_State_Plan_on_Elimin ating_HCV_Final_Draft_720817_7.pdf. Accessed Dec 2021.

32. DeBose-Scarlett A, Balise R, Kwon D, Vadaparampil S, Chen SX, Schiff ER, et al. Obstacles to successful treatment of hepatitis $\mathrm{C}$ in uninsured patients from 
a minority population. J Transl Med. 2018;16(1): 178.

33. Im DCS, Reddy S, Hawkins C, Galvin S. Characteristics and specialist linkage to care of patients diagnosed with chronic hepatitis $\mathrm{C}$ across different settings in an urban academic hospital: implications for improving diagnosis and linkage to care. Front Microbiol. 2021;12:576357.

34. Justia.com. Hoffer v. Secretary, Florida Departmental Corrections, No. 19-11921 (11th Cir. 2020) 2020. https://law.justia.com/cases/federal/appella te-courts/ca11/19-11921/19-11921-2020-08-31.html. Accessed Mar 2021.

35. WUSF public media. Gov. DeSantis vetoes $\$ 1$ billion from Florida budget, citing "difficult circumstances". https://wusfnews.wusf.usf.edu/politics/ 2020-06-29/gov-desantis-vetoes-1-billion-from-floridabudget-citing-difficult-circumstances. Accessed Dec 2021.
36. Applegate TL, Fajardo E, Sacks JA. Hepatitis C virus diagnosis and the Holy Grail. Infect Dis Clin N Am. 2018;32(2):425-45.

37. Washington State Department of Health. Hep C free Washington: plan to eliminate hepatitis C in Washington State by 2030 2019. https://www.doh. wa.gov/Portals/1/Documents/Pubs/150nonDOH-Hep CFreeWA-PlanJuly2019.pdf. Accessed Dec 2021.

38. Wingrove C, Ferrier L, James C, Wang S. The impact of COVID-19 on hepatitis elimination. Lancet Gastroenterol Hepatol. 2020;5(9):792-4.

\section{Publisher's Note}

Springer Nature remains neutral with regard to jurisdictional claims in published maps and institutional affiliations. 